\title{
LA MUTACIÓN CONSTITUCIONAL DETRÁS DE LA INCONSTITUCIONALIDAD QUE AFECTÓ AL IMPUESTO SOBRE EL SERVICIO DE ALUMBRADO PÚBLICO EN COLOMBIA*
}

Carlos Arturo Duarte Martínez**

Recibido: Febrero 17 de 2017

Aprobado: Mayo 11 de 2017

\section{RESUMEN}

Se demuestra que ha ocurrido un cambio normativo radical o intenso del contenido de la Constitución de 1991 referente a la potestad tributaria de las entidades territoriales para regular sus impuestos. Aquel es generado por la variación del criterio jurisprudencial de la Corte Constitucional en el desarrollo interpretativo del texto constitucional, sin que se presente alguna alteración en su tenor literal. Esa transformación genera la inconstitucionalidad del impuesto sobre el servicio de alumbrado público.

Palabras clave: Mutación constitucional, impuesto territorial, alumbrado público, autonomía territorial.

\section{CONSTITUTIONAL MUTATION BEHIND THE UNCONSTITUTIONALITY THAT AFFECTS PUBLIC LIGHTING SERVICE TAX IN COLOMBIA}

\begin{abstract}
This article demonstrates that there has been a radical or intense normative change of the contents of the Political Constitution of Colombia regarding the tax authority of the territorial entities to regulate their taxes. This normative

\footnotetext{
*Este texto fue presentado como una comunicación en el XII Congreso Iberoamericano de Derecho constitucional, que tuvo lugar en septiembre de 2015 en la Universidad Externado de Colombia

** Abogado y especialista en Derecho público de la Universidad Autónoma de Bucaramanga (UNAB). Maestrando en Derecho constitucional de la Universidad Externado de Colombia. Docente auxiliar de la Facultad de Derecho y miembro del Grupo de Investigación en Hermenéutica Jurídica del Centro de Investigaciones Socio-Jurídicas “Laureano Gómez Serrano" de la UNAB. cduarte3@unab.edu.co
} 
change is generated by the variation of the jurisprudential criterion of the Constitutional Court in the interpretative development of the constitutional text, without modifying its literal meaning. This transformation generates the unconstitutionality of public lighting service tax.

Key words: Constitutional mutation, territorial tax system, public lighting service, territorial autonomy

\section{A MUTAÇÃO CONSTITUCIONAL POR TRÁS DA INCONSTITUCIONALIDADE QUE AFETOU O IMPOSTO SOBRE O SERVIÇO DE ILUMINAÇÃO PÚBLICA NA COLÔMBIA}

\section{RESUMO:}

Se demonstra que tem acontecido uma mudança normativa radical ou intensa do conteúdo da Constituição de 1991, relativo ao poder de tributação das entidades territoriais para regular seus impostos. Aquele é gerado pela variação do critério jurisprudencial do Tribunal Constitucional no desenvolvimento interpretativo do texto constitucional, sem que se apresente alguma alteração em sua formulação. Esta transformação gera a inconstitucionalidade do imposto sobre o serviço de iluminação pública.

Palavras-chave: mutação constitucional, imposto sobre a terra, iluminação pública, autonomia territorial.

\section{INTRODUCCIÓN}

La Corte Constitucional generó una mutación en la Constitución de 1991 en el punto de la potestad tributaria de los entes territoriales. Dicho cambio emerge al confrontar la comprensión definitivamente asumida por la Corte en el periodo 1993 y 2003 -siendo la última de ellas la Sentencia C-1043 de 2003-, según la cual el legislador debe autorizar la creación del impuesto territorial, y determinar cualquiera de sus elementos, correspondiendo a Asambleas y Concejos establecer lo no previsto en la ley; y el criterio desarrollado a partir de la Sentencia C-992 de 2004 en donde la Corte dispuso que el Congreso de la República siempre debe establecer su hecho generador.

El "test de intensidad" de la transformación del contenido normativo de la constitución se da como positivo con la inconstitucionalidad sobreviniente que sufrió el impuesto sobre el servicio de alumbrado público, cuya exequibilidad con la Constitución de 1991 fue establecida, 80 
bajo la primera comprensión de la Corte Constitucional, en la Sentencia C-504 de 2002, pero que no se corresponde con el nuevo contenido normativo constitucional debido a que no es posible determinar a partir de la ley-en sentido formal-su hecho generador.

Se sostiene que esta inconstitucionalidad sobreviniente no se supera con el hecho generador establecido jurisprudencialmente por el Consejo de Estado, pues en la integración normativa de la que él resulta se integran actos administrativos, lo que es una transgresión al principio de legalidad tributaria. Esta situación es prueba de que el hecho generador del impuesto sobre el servicio de alumbrado público no fue determinado a partir de la ley.

Lo anterior pasa a ser sustentado en cuatro apartados. En el primero se expone la teoría dinámica-normativa de mutación constitucional defendida por el profesor externadista Carlos López (2015), que se acoge para el desarrollo del presente texto, y su articulación con la precaria jurisprudencia de la Corte Constitucional colombiana sobre el asunto. Enseguida, se expone la enunciada mutación constitucional, esto es, los criterios jurisprudenciales desarrollados por la Corte Constitucional sobre las competencias compartidas entre el Congreso y las Asambleas y Concejos para la configuración del tributo territorial. En el tercer apartado se analizará el impuesto sobre el alumbrado público a partir de los dos últimos criterios jurisprudenciales, incluyendo los debates dados en el Consejo de Estado alrededor de la determinación de su hecho generador; y la regulación que trajo la Ley 1753 de 2015 relacionado con los hechos generadores de la "contribución especial con destinación específica" para el servicio público esencial de alumbrado público. Finalmente se plantearán las conclusiones.

\section{LA TEORÍA DINÁMICA-NORMATIVA DE LA MUTACIÓN CONSTITUCIONAL}

\subsection{Concepto, justificación y límites}

En su tesis doctoral ${ }^{1}$, el profesor López (2015) propone un concepto de mutación acorde con la Constitución colombiana de $1991^{2}$ y sus principios de fuerza normativa, supremacía y rigidez.

1 Mutación de los derechos fundamentales por la interpretación de la Corte Constitucional colombiana. Concepto, justificación y límites. Bogotá: Universidad Externado de Colombia, 2015.

2 Aunque la tesis doctoral versa sobre derechos fundamentales, es aplicable al objeto de este texto en cuanto que, como el profesor López advierte, parte de nociones generales sobre la mutación constitucional. Es decir, las mutaciones constitucionales pueden operar en las partes dogmática y orgánica de una Constitución. El caso que aquí se analiza opera en la parte orgánica de la Constitución colombiana de 1991. 
El profesor López asume la mutación constitucional como una consecuencia de la conexión entre el texto constitucional y la realidad constitucional. Texto y realidad, respectivamente, constituyen la faceta normativa y dinámica del concepto de mutación constitucional. La faceta dinámica está constituida por hechos sociales, que deben ser jurídicos para tener cabida en la disposición constitucional cuyo contenido mutan.

La exclusión de hechos extra-jurídicos como causa de las mutaciones, permite identificar límites constitucionales dentro de los cuales deben moverse para ser admisibles. Si se permite este símil, así como no hay costumbre contra legem, tampoco puede admitirse la mutación contra constitutionem. Sierra Porto (1998) señala que la mutación constitucional "debe respetar el texto constitucional mutado, en el sentido de que no puede hablarse de mutación cuando el precepto no pueda ser comprendido en forma razonable bajo ninguno de sus posibles significados" (p. 35). No es posible valorarse a la mutación constitucional como una reforma informal a la Constitución. Las reformas a la Constitución sólo pueden ser formales, esto es a través de los mecanismos establecidos para ello. ${ }^{3}$

Bajo las anteriores premisas, se formula por el profesor externadista el concepto de mutación constitucional con los siguientes elementos: (i) "significa una transformación intensa o radical del contenido normativo" de la Constitución, (ii) "Sin que se advierta ninguna alteración en el tenor literal de [sus] normas". Y se ocasiona (i) "por la evolución histórica de la sociedad" donde la Constitución se aplica -faceta dinámica-, (ii) o "por la variación del criterio jurisprudencial por parte del juez en relación con unos hechos prácticos existentes", en el marco de la interpretación de la Constitución -faceta normativa(López, 2015, p. 169).

Para el profesor López las normas constitucionales están compuestas por:

Una parte normativa explícita (disposiciones constitucionales, normas infraconstitucionales, la jurisprudencia sobre el particular, etc.), [así] como por la parte normativa no explícita, esto es, por la práctica social o el momento histórico, pues... [hay] un contenido empírico o fundado en la realidad social, del que se nutren y sobre el cual proyectan su fuerza normativa. 
El contenido normativo se compone de todo el texto jurídico del precepto constitucional. El profesor López propone la distinción entre contenido "en sentido amplio" y "en sentido estricto", que se edifican a partir de los momentos de la Constitución. Ambos sentidos de contenido normativo se componen por: (i) los valores y principios que el precepto expresa y demás disposiciones constitucionales relacionadas, y (ii) la realidad constitucional.

En el contenido en sentido amplio la realidad constitucional es el momento constituyente. Es "amplio" debido a que en el momento constituyente "no ha sido concretado, especificado, pormenorizado o detallado". El contenido en sentido estricto encierra su realidad constitucional en un momento histórico posterior al momento constituyente. El profesor López no señala un parámetro temporal -normativamente no se puede hacer- pero se entiende que la dinámica social y la praxis constitucional llevan a concretar el contenido normativo, que se plantea "en sentido estricto" pues "se encuentra mejor delimitado, es menos abierto, abstracto y vago" (López, 2015, pp. 175177).

El tiempo de las mutaciones no es el momento constituyente, sostiene el profesor López. Así, la mutación produce una transformación del contenido normativo de la Constitución en sentido estricto. Esto ocurre pues en el tiempo cercano al momento constituyente no hay "punto de referencia" determinado para contrastar la realidad y encontrar un cambio; mientras que tiempo después, menciona:

Es mucho más perceptible la presencia de mutaciones, pues existe un contenido normativo previo y explicitado que sirve de referente para contraponer la descripción de una nueva situación constitucional que puede producir un cambio intenso en ese contenido previamente existente (López, 2015, p. 177).

Pues bien, el contenido normativo se transforma de la siguiente manera:

- "Por la evolución histórica de la sociedad": hay una variación en la ideología fundante de la colectividad, bien sea porque esa ideología produce nuevos hechos prácticos, o cuando avala unos nuevos.

- "Por la variación del criterio jurisprudencial": no hay ningún cambio fáctico, hay "una realidad que sigue siendo la misma", pero el juez constitucional adopta un "nuevo razonamiento más idóneo para lograr la eficacia del 'precepto constitucional' frente a unos hechos 
prácticos existentes". La posibilidad de cambio, se afinca en la autonomía interpretativa de los jueces (López, 2015,p.188).

Finalmente, la existencia de la mutación constitucional depende de la ocurrencia de un cambio intenso en el contenido normativo de la Constitución. Esto se prueba con el desarrollo de una especie de test de intensidad del cambio, que permite diferenciar el simple proceso de concreción de la Constitución, de su transformación. La disimilitud entre estos fenómenos es de grado. La mutación es una modificación en alto grado del contenido normativo en sentido estricto de una norma constitucional.

Se propone que una manera de determinar la intensidad que da vida a la mutación constitucional, como ocurre en el asunto que aquí se analiza, es la ocurrencia de inconstitucionalidades sobrevinientes. Entre aquella y estas, hay la misma relación que existe entre el humo y el fuego.

\subsection{Articulación del concepto de mutación con los pro- nunciamientos de la jurisprudencia de la Corte Constitucional colombiana}

El tema de las mutaciones constitucionales no ha tenido un desarrollo jurisprudencial comparable con el de la doctrina. Ha sido tratado de manera tangencial por los jueces, y sin el expreso reconocimiento de ser un cambio de la Constitución sin reforma de su texto.

La anterior situación, en todo caso, no impide acercar ciertos pronunciamientos de la Corte Constitucional colombiana a partir del concepto de mutación constitucional. Resulta curioso pero la Corte Constitucional, alude de manera expresa a la mutación constitucional para combatirla. En una providencia se destaca que "no hay reforma [a la Constitución] sin modificación de los textos" (Corte Constitucional, sentencia C-588, 2009).

Destaca la Corte en esta ocasión la importancia que tiene la reforma constitucional "con el objetivo de que se cumplan idénticos propósitos a los perseguidos por la Constitución original, escrita y vertida en un documento único", de modo tal que no tengan ninguna "oportunidad la introducción de modificaciones tácitas o de imposible, difícil o dudoso conocimiento".

No obstante lo anterior, la Corte Constitucional no ha desconocido que la realidad no puede ser captada en fórmulas fijas por la Constitución de 84 
1991, y sin llamar a la mutación por su nombre sí ha abierto la posibilidad de que la Constitución cambie sin la reforma de su texto.

Lo anterior se observa en el Auto 223 de 2006, en el que la Corte expone que le es posible cambiar su precedente constitucional por: "(i) los cambios que el Constituyente introduzca en la normatividad; (ii) la evolución que vayan mostrando los hechos de la vida en sociedad y (iii) los nuevos enfoques que promueva el desarrollo del pensamiento jurídico.”

El primer evento implica un cambio en el texto de la Constitución, bien sea por la expedición de una nueva Constitución o por la adopción de una reforma o enmienda que consagren una regulación diferente. El parámetro para realizar el control de constitucional sufre un cambio en su texto.

La evolución de los hechos sociales y la adopción de nuevos enfoques jurídicos son el campo de las mutaciones constitucionales. Es más, este pronunciamiento judicial se articula con la tesis dinámica-normativa de la mutación constitucional defendida por el profesor López (2015) ${ }^{4}$. Los hechos sociales se encargan de generar cambios normativos de preceptos constitucionales como "evolución histórica de la sociedad", y los nuevos enfoques del pensamiento jurídico generan "la variación de criterios jurisprudenciales", esto es que deben ser adoptados por la Corte Constitucional.

En esos dos eventos, el parámetro constitucional a partir del cual se define la subordinación de la ley no varía en su texto, que permanece inalterado. Sin embargo, su contenido normativo no es el mismo, lo que abre la oportunidad a nuevos pronunciamientos de la Corte.

Y si la Corte resalta estas situaciones como justificantes para variar su jurisprudencia, quiere decir entonces que los hechos sociales cambiados, y los novedosos enfoques del pensamiento jurídico, hacen perder efectos de cosa juzgada a sus decisiones anteriores. A partir de los "hechos de la vida en sociedad" que cambian y el pensamiento jurídico que promueve "nuevos enfoques", resultan contenidos normativos constitucionales que se dejan atrás y otros que rigen hacia el futuro.

Los eventos de mutación constitucional señalados en el Auto 223 de 2006 representan un nuevo contexto normativo a partir del cual pueden

4 La relación entre esta decisión de la Corte y la tesis del profesor externadista no es excluyente a otras nociones de mutación constitucional. 
volverse a decidir asuntos que se consideraban ya resueltos. De tal suerte que si los vestigios o rezagos normativos que se justificaban a partir de la anterior sociedad o modo de entender el Derecho resultan incompatibles con el nuevo contenido normativo del precepto constitucional mutado, deben ser excluidos del ordenamiento jurídico por el guardián de la Constitución.

La idea de las mutaciones constitucionales como resultado de la conexión entre texto constitucional y realidad constitucional, hacen que la Corte no sea un albacea de la Constitución escrita y sus reformas de modo que se encargue de anclar el futuro constitucional al momento constituyente. La Corte Constitucional es una protectora y promotora del cambio constitucional, que se da a partir de los hechos sociales y corrientes del pensamiento jurídico, siempre que sean admisibles en los límites de la Constitución. El Auto 223 de 2006, sin duda, plantea de manera contundente que la Corte Constitucional no es un cancerbero del stato quo, sino que también está sujeta y da vida a las transformaciones de la realidad y del Derecho.

Finalmente, cabe resaltar que el deficiente desarrollo de la mutación constitucional hace que choque con figuras con las que necesariamente se vincula, caso de la inconstitucionalidad sobreviniente.

Este fenómeno jurídico - dijo la Corte en la Sentencia C-155 de 1999"se presenta cuando estando una norma [legal] vigente, aparece una nueva disposición de rango constitucional contraria a lo reglado en la primera". Es decir que ocurre un cambio o reforma a la Constitución y la norma legal preexistente resulta en contradicción con la nueva norma superior. También se da "por los nuevos hechos del legislador" que ocurre "cuando la reforma de una disposición legal implica la modificación de aspectos sustantivos del precepto... de modo tal que la norma resultante viola disposiciones constitucionales" (Corte Constitucional, Sentencia C-287, 2009).

Con lo visto hasta aquí puede concluirse que el anterior catálogo está incompleto. Como productora de cambios normativos a disposiciones que fungen de parámetro en el control de constitucionalidad, una mutación tiene la fuerza normativa de generar inconstitucionalidades sobrevinientes. No podría sustentarse la validez de una norma legal si repulsa a la nueva ideología adoptada por la sociedad o a los hechos que ahora ella acoge, o que se opone a las transformaciones surgidas de un razonamiento más idóneo para dar efícacia a normas constitucionales y que e incorpora con un cambio en la jurisprudencia constitucional, en 86 
eventos en que generen un nuevo contenido normativo distinto al existente antes de su ocurrencia. La regulación del impuesto de alumbrado público sufrió una inconstitucionalidad sobreviniente entre 2004 y 2015.

\section{LA MUTACIÓN CONSTITUCIONAL DE LA POTESTAD TRIBUTARIA RECONOCIDA A LAS ENTIDADES TERRITORIALES EN LA CONSTITUCIÓN DE 1991}

\subsection{Constitución de 1886 y organización estatal}

La Constitución de 1886 marcó una línea centralista de la organización estatal en lo político y en lo administrativo para Colombia. De un Estado federal -adoptado en la Constitución de 1863-se pasó a un Estado unitario.

Respecto de la organización del Estado en la última Constitución decimonónica colombiana, la profesora Paula Robledo (2010) sintetiza que se estableció "una organización territorial totalmente jerarquizada que se desarrolló en medio de un Estado confesional en el que las libertades públicas, el principio democrático y la descentralización territorial sufrían un detrimento paulatino"(p. 205).

En el ámbito de la autonomía financiera de las entidades territoriales, no se dieron a nivel constitucional importantes desarrollos en su componente fiscal sino desde el Acto legislativo 02 de 1987, mediante el cual expresamente se reconoció a las entidades territoriales la propiedad exclusiva sobre sus bienes y rentas. Esta reforma constitucional fue parte de unos cambios introducidos al diseño estatal para dotar de autonomía a las regiones, como el Acto Legislativo 01 de 1986 que estableció la elección popular de alcaldes.

\subsection{Las ambiguas disposiciones de la Constitución de 1991 sobre la potestad tributaria}

El momento constituyente de 1991 deparó trascendentales cambios a la organización territorial del Estado colombiano. La centenaria Constitución de 1886 tenía a las hoy entidades territoriales lánguidas para la gestión de sus propios asuntos.

Esta situación fue de interés para la Asamblea Nacional Constituyente de 1991. Así, uno de los copresidentes de la Junta Preparatoria de la Asamblea Constituyente, en su instalación el cinco de febrero, siendo sexto en el orden de intervinientes, dando un golpe de pecho a nombre 
de la inmensa mayoría del país, manifestaba a sus compañeros que "de nada sirven la elección popular de alcaldes -ni la propuesta de gobernadores-, ni la asunción de servicios y competencias que antes detentaba la Nación, si a esa autonomía política y administrativa de los territorios no se le dota fiscalmente" (Abello, 1991, p. 12).

Este ímpetu constituyente por dar autonomía fiscal a las entidades territoriales, no se plasmó en la Constitución de 1991 con una regulación clara. Si bien en su Título XI "De la organización territorial" establece como potestad de las entidades territoriales el "establecer los tributos necesarios para el cumplimiento de sus funciones" (art. 287.3); también le reconoce facultad impositiva al Congreso de la República, con unas disposiciones particularmente confusas. Véase la siguiente comparación de normas:

Tabla No. 1. Disposiciones constitucionales relacionadas con la imposición de tributos.

\begin{tabular}{|l|l|l|}
\hline Congreso de la República & Asambleas Departamentales & \multicolumn{1}{|c|}{ Concejos Municipales } \\
\hline $\begin{array}{l}\text { Artículo 150. Corresponde al } \\
\text { Congreso hacer las leyes. Por }\end{array}$ & $\begin{array}{l}\text { Artículo 300. Corresponde a } \\
\text { las Asambleas Departamen- } \\
\text { medio de ellas ejerce las } \\
\text { tales, por medio de ordenan- }\end{array}$ & $\begin{array}{l}\text { Artículo 313. Corresponde a } \\
\text { los concejos: } \\
\text { siguientes funciones: }\end{array}$ \\
$\begin{array}{ll}\text { zas: } \ldots) & \text { V. Votar de conformidad con } \\
\text { 12. Establecer contribu-ciones } & \text { la Constitución y la ley los } \\
\text { fiscales y, excep-cionalmente, } & \text { Decretar, de conformidad } \\
\text { tributos y los gastos locales. } \\
\text { contribuciones parafiscales en la Ley, los tributos y } \\
\text { los casos... }\end{array}$ & $\begin{array}{l}\text { contribuciones necesarios } \\
\text { para el cumplimiento de las } \\
\text { funciones departamentales. }\end{array}$ & \\
\hline
\end{tabular}

Para reafirmar la indeterminación en las competencias de quienes ejercen potestad tributaria en el Estado colombiano, el final del primer inciso del artículo 338 dice: "La ley, las ordenanzas y los acuerdos deben fijar, directamente, los sujetos activos y pasivos, los hechos y las bases gravables, y las tarifas de los impuestos".

Esta indeterminación en las disposiciones normativas abrió la puerta para que la Corte empezara a fijar un parámetro más o menos determinado en el reparto de competencias tributarias entre la nación y las entidades territoriales. En dicha labor la Corte Constitucional tuvo que conciliar los principios de reserva de ley y autonomía municipal. El primero jalona la determinación de los elementos del tributo territorial por la ley -en sentido formal-, mientras que el segundo reclama la participación de las entidades territoriales en la configuración de esa obligación tributaria.

La jurisprudencia de la Corte Constitucional sobre el tema puede dividirse en dos grandes momentos: el primero comprende el periodo 1993-2003, y 88 
el segundo desde 2004 hasta hoy. En ellos se consolidan los contenidos amplio y estricto de las potestades tributarias del Congreso de la República y de las Asambleas Departamentales y Concejos Municipales.

\subsection{El tránsito de un contenido normativo en sentido amplio a uno estricto y propio de la Constitución de 1991}

En este primer momento se cuenta con decisiones de la Corte que no tienen un parámetro de contraste que las pueda constituir en mutación constitucional. Dicha década puede ser divida en dos periodos.

(i) El primero comprende las Sentencias C-004 de 1993, C-070 de 1994, C-205 de 1995, C-486 de 1996 y C-583 de 1996, en las que la Corte da una marcada prevalencia del principio de reserva de ley en la configuración del tributo municipal.

En estas sentencias, la Corte determina que: a) le corresponde exclusivamente al Congreso crear y definir los elementos de los tributos territoriales, b) mientras que los entes territoriales tienen a cargo "la decisión de adoptar o no los tributos territoriales establecidos en la ley" (Robledo, 2010, p. 391).

Puede decirse que esta temprana jurisprudencia cargaba con la herencia centralista de la Constitución de 1886. Sólo respondía tímidamente al interés constituyente de dar autonomía tributaria a las entidades territoriales. Al seguir una postura de tradición centralista pareciera que la Corte Constitucional, en sus primeros años, de cierta forma no asume el cambio de Constitución en el punto de Derecho aquí estudiado, situación motivada seguramente por una prevención ante los anotados defectos del nuevo texto constitucional.

(ii) El segundo período presenta posturas en las que la Corte Constitucional va a atenuar el principio de reserva de la ley tributaria, en beneficio del principio de autonomía tributaria de las entidades territoriales:

- En la C-084 de 1995 sostiene que el impuesto territorial se ajusta a la Constitución inclusive cuando los entes territoriales definan sus elementos a partir de la ley que lo crea. Bien puede la ley establecer el tributo, o autorizar su creación, dice la Corte. En el primer evento es el Congreso quien determina los elementos de la obligación tributaria, en el segundo lo hacen las Asambleas y los Concejos Municipales. 
- En la C-537 de 1995 se sostiene que la constitucionalidad del tributo territorial puede establecerse cuando a pesar de las deficiencias legislativas, de "su texto es posible deducir una interpretación razonable" que indique sus elementos.

- El proceso de ampliar la autonomía tributaria se sigue consolidando, hasta llegar a la Sentencia C-504 de $2002^{5}$, en la que la Corte concluye que la Constitución no exige que la ley establezca todos los elementos del tributo territorial, sino que como mínimo debe crearlo y regular al menos uno de ellos -que puede ser cualquiera, pues no específica alguno-. Para Robledo (2010), este pronunciamiento es extremo pues admite "disposiciones que autorizan a los concejos municipales a gravar una determinada actividad, sin indicar más elemento del concreto tributo que la pura mención de la materia sobre el cual recae" (p. 397).

- En la Sentencia C-035 de 2009, la Corte plantea que no viola la Constitución el tributo que no encuentre en la ley la determinación de alguno de sus elementos, siempre que sea determinable a partir de ella. De esta sentencia, la profesora Robledo (2015) resalta que "no aclaró qué elemento de la obligación tributaria puede faltar" (p. 400).

Las providencias de este segundo grupo delimitan el contenido normativo de la potestad tributaria de la Constitución de 1991. La Corte Constitucional se desliga del férreo centralismo de la Carta de 1886, e interpreta, ahora sí, las disposiciones de 1991 en el marco de un Estado unitario y descentralizado, dando más peso al principio de autonomía tributaria de las entidades territoriales. Queda pues edificada la medida con la que se constatará el cambio de criterio jurisprudencial que transforma su contenido normativo en "sentido específico".

\subsection{El cambio del contenido normativo en sentido estricto}

El cambio de criterio jurisprudencial que determina un nuevo contenido normativo en sentido estricto de las disposiciones constitucionales que reconocen potestad tributaria al legislador y a las entidades territoriales se da en la Sentencia C-992 de 2004, cuando la Corte señala que por lo menos el Congreso de la República debe fijar el hecho generador del tributo territorial.

El nuevo criterio jurisprudencial se edifica por la necesidad de garantizar la seguridad jurídica y, en especial, de preservar el carácter unitario del Estado colombiano. Con esta tesis, la Corte se asegura de que la potestad 
tributaria atribuida constitucionalmente a las entidades territoriales no se convierta en una "soberanía tributaria", propia de los territorios en los Estados federados, esto por cuanto que:

En la medida en que el hecho gravable o hecho imponible 'es el elemento que en general mejor define el perfil específico de un tributo', sin lugar a dudas es un elemento que tiene que estar precisado por la ley que autoriza la creación de un tributo territorial (Corte Constitucional de Colombina, Sentencia C.992, 2004) (subrayas añadidas).

Líneas seguidas añadió que "debido a que la identidad del impuesto se encuentra íntimamente ligada al hecho gravable, es claro que la ley debe delimitar los hechos gravables que son susceptibles de ser generadores de impuestos territoriales" (subrayas añadidas). Este criterio ha sido reiterado, por ejemplo, en las Sentencia C-035 de 2009 y C-459 de 2013.

La intensidad de la mutación constitucional, según se vio más atrás, se identifica por un alto grado de cambio del contenido normativo del precepto constitucional, sin que llegue a desbordar los límites de la Constitución. En las decisiones hasta ahora analizadas, se ha debatido teniendo como fundamentos y límites los principios de reserva de ley y autonomía tributaria de las entidades territoriales. Las sentencias en mayor o menor medida han dado prevalencia a uno u otro, hasta llegar en un equilibrio a partir de la Sentencia C-992 de 2004.

Pero este equilibrio no es baladí. A partir de él se presta importancia a un posible conjunto de tributos territoriales que con anterioridad eran iusconstitucionalmente irrelevantes: aquellos cuya imposición fue autorizada por la ley, pero que carecen de hecho generador determinado o determinable a partir de ella. En esta situación se encuentra el impuesto sobre el servicio de alumbrado público.

\section{EI IMPUESTO SOBRE EL SERVICIO DE ALUMBRADO PÚBLICO}

\subsection{Consagración legal}

La Ley 97 de 1913 en el literal d) de su artículo $1^{\circ}$ crea el "Impuesto sobre el servicio de alumbrado público". Este es su texto:

Artículo $1^{\circ}$. El Concejo Municipal de la ciudad de Bogotá puede crear libremente los siguientes impuestos y contribuciones, 
además de los existentes hoy legalmente; organizar su cobro y darles el destino que juzgue más conveniente para atender a los servicios municipales, sin necesidad de previa autorización de la Asamblea Departamental:

(...)

d) Impuesto sobre el servicio de alumbrado público.

Luego mediante la Ley 84 de 1915 (art. 1 Lit. a) se extendió dicha potestad a todos los municipios del país.

Debe decirse que esta regulación es ambigua, pues no se sabe qué es lo que se está gravando fiscalmente. El término "sobre" tiene dos significados lingüísticos: (i) "encima de", o también (ii) "acerca de", es decir "sobre aquello de que se trata". Según estas acepciones, la frase podría indicar cualquiera de estas acciones: que el impuesto se aplicará al costo del servicio de alumbrado público (encima de), o que se creará un impuesto que será entregado al servicio de alumbrado público (acerca de).

A partir del principio de interpretación del efecto útil, se acoge el segundo significado señalado, según el cual el legislador busca una fuente de financiamiento para el servicio público de alumbrado público que está a cargo de los municipios.

Finalmente, es de resaltar que las disposiciones legales anotadas sólo dan claridad en que el sujeto activo del impuesto sobre el servicio de alumbrado público es cada municipio.

\subsection{La Sentencia C-504 de 2002}

En esta providencia la Corte determina la constitucionalidad de este tributo territorial. Con la ratio decidendi atrás señalada, la decisión no podía ser otra: la ley autoriza la imposición del tributo y establece uno de sus elementos: el sujeto activo.

Para el momento en que esta decisión de toma, la exigua regulación en la ley del impuesto de alumbrado público estaba acorde con el contenido normativo propio de la Constitución de 1991 sobre la potestad tributaria de las entidades territoriales construido por la Corre Constitucional.

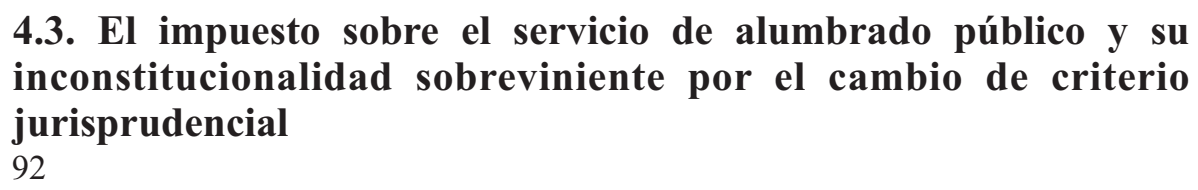

4.3. El impuesto sobre el servicio de alumbrado público y su inconstitucionalidad sobreviniente por el cambio de criterio jurisprudencial 
Como tributo de carácter territorial debe, según las Sentencias C-992 de 2004, C-035 de 2009 y C-459 de 2013, tener previsto su hecho generador en la ley. Alrededor del hecho generador del impuesto sobre el servicio de alumbrado público se dio un intenso debate en la Sección Cuarta del Consejo de Estado, cerrado en 2015 con la aparición de la Ley 1753.

Esta corporación judicial en Sentencia del 17 de julio de $2008^{6}$, que desata una demanda de simple nulidad en contra de un acuerdo municipal que regulaba el impuesto sobre el alumbrado público, sin citar la C-992 de 2004 concluye que: "es el Congreso a través de la Ley quien debe determinar el hecho generador del tributo y a partir de ella, podrán las asambleas o los concejos ejercer su poder de imposición desarrollando los demás elementos de la obligación".

Y al tratar de determinar si "el servicio de alumbrado público" podía ser un hecho generador lo desestima a cuenta de su indeterminación. Así ejemplificó:

Si el hecho generador es la iluminación de espacios de libre circulación, no hay claridad sobre lo que se pretende gravar. Si se dijera que es el simple tránsito por dichos lugares, no hay certidumbre sobre cuál es el indicador de capacidad contributiva. Si por el contrario es la propiedad de un bien inmueble o la realización de actividades dentro del municipio, no es evidente su relación con la iluminación de bienes de uso público. Tampoco puede considerarse como el costo del servicio ni como retribución por el beneficio obtenido, pues no es posible identificar la persona que percibe directamente el servicio de alumbrado y en particular la manera de determinar la proporción del beneficio (Consejo de Estado, sentencia del 17 de julio, 2008).

Más adelante dijo:

Esta indeterminación del hecho generador conlleva a que sean $\underline{\text { los }}$ concejos municipales o distritales los que creen el objeto del tributo y los hechos económicos reveladores de capacidad contributiva para el impuesto de alumbrado público, lo cual resulta inadmisible en el ordenamiento constitucional actual porque ello implicaría que cada ente territorial pueda crear bajo la misma denominación, gravámenes totalmente diferentes sin

6 Consejo de Estado. Sala de lo Contencioso Administrativo. Sección Cuarta. C.P.: Ligia López Díaz. Rad.: 07001-23-15-000-2005-00203-01(16170). Empresa de Energía de Arauca Vs. Municipio de Saravena. 
ningún límite legal y cuyos elementos esenciales no se identifiquen entre sí (subrayas añadidas).

Estas consideraciones que se constituían en obiter dicta en dicha providencia ${ }^{7}$, se reiterarían como ratio decidendi en la Sentencia del 04 de septiembre de $2008^{8}$.

Pero esta tesis jalonada por la Consejera Ligia López no perduraría. A casi un año de su aparición sería dejada atrás por la nueva conformación de la Sección Cuarta ${ }^{9}$ del Consejo de Estado en la Sentencia del 09 de julio de $2009^{10}$. En dicha decisión, aunque se analiza otro de los impuestos establecidos en la Ley 97 de 1913, se hace referencia explícita a la pérdida de aplicabilidad del impuesto de alumbrado. Igualmente sin referenciar las Sentencias C-504 de 2002 y C-992 de 2004, la postura ahora asumida por el Consejo de Estado reconocía que los entes territoriales no tienen autonomía ilimitada en materia tributaria pero que "de conformidad con las pautas dadas por la Ley, pueden establecer los elementos de la obligación tributaria cuando aquélla no los haya fijado directamente”. ¿Cuáles?, cualquiera, pues no se específica.

Esto último conlleva a que si la ley que crea un tributo territorial no es del todo exacta, de conformidad con el artículo 338 superior, (i) sean los entes territoriales quienes superen la indeterminación de los elementos del tributo por decisión de las Asambleas Departamentales y los Concejos Municipales, y que (ii) ello se plasme en actos administrativos: Ordenanzas Departamentales y Acuerdos Municipales.

El pronunciamiento de la "nueva" Sección Cuarta sobre el impuesto de alumbrado público tardaría en llegar un par de meses. En Sentencia del 11 de marzo de $2010^{11}$ se estudiaba la legalidad de un acuerdo municipal que estableció el impuesto de alumbrado público a las empresas cuyos oleoductos atravesaran la jurisdicción del Municipio.

7 El acuerdo que tenía como sujeto pasivo del impuesto de alumbrado público "a los comercializadores del servicio público domiciliario de energía”, fue declarado nulo por violar el artículo 24.1 de la Ley 142 de 1994 que prohíbe a los entes territoriales gravar a las empresas de servicios públicos domiciliarios con tributos "que sean aplicables a los demás contribuyentes que cumplan funciones industriales o comerciales.".

8 Consejo de Estado. Sala de lo Contencioso Administrativo. Sección Cuarta. C.P.: Ligia López Díaz. Sentencia del 04 de septiembre de 2008. Rad.: 76001-23-31-000-2005-04582-01(16850).

9 Secundaron a la Consejera Ligia López, los Consejeros María Inés Ortiz Barbosa, Juan Ángel Palacio Hincapié y Héctor Romero Díaz. En julio de 2009 sólo continuaba el último de ellos quien salvó el voto en el cambio de jurisprudencia.

10 Consejo de Estado. Sala de lo Contencioso Administrativo. Sección Cuarta. C.P.: Martha Teresa Briceño de Valencia. Sentencia del 09 de julio de 2009. Rad.: 17001-23-31-000-2006-00404-02 (16544). Néstor Fabio Valencia Torres y otro Vs. Municipio de Manizales.

11 Consejo de Estado. Sala de lo Contencioso Administrativo. Sección Cuarta. C.P.: Hugo Fernando Bastidas Bárcenas. Sentencia del 11 de marzo de 2010. Rad.: 54001-23-31-000-2004-01079-00(16667). 
En esta decisión el Consejo de Estado señala la diferencia entre el hecho generador y el objeto imponible del tributo, citando un pronunciamiento anterior que define a este último como el "elemento de la realidad que selecciona el legislador para establecer el tributo y que existe antes de la aparición del tributo, tales como, la renta, el patrimonio, el consumo" ${ }^{12}$.

Frente a la ley 97 de 1913, el Consejo de Estado reconoce que el legislador consagra apenas el objeto del tributo, que es el "alumbrado público", y acepta que su hecho generador "se ha venido decantando a partir de la regulación que, sobre el particular, han proferido autoridades nacionales como la Comisión de Regulación de Energía y Gas (en adelante CREG) y el Ministerio de Minas y Energía" (Consejo de Estado, Sentencia del 14 de julio, 2016).

Particularmente cita la Resolución CREG 043 de 1995, el Decreto Reglamentario 2424 de 2006 -normas de regulación económica- y concluye que el hecho generador es "ser usuario potencial receptor de ese servicio" $"$.

Ante estos pronunciamientos puede destacarse que la Sección Cuarta se contradice al señalar primero que los entes territoriales pueden establecer a partir de la ley los elementos del tributo territorial cuya claridad no se prevea en aquella, para después esforzarse en construir el hecho generador del impuesto sobre el servicio de alumbrado público a partir de actos administrativos que no son proferidos por las autoridades nacionales a los que la Constitución colombiana de 1991 no les confiere potestad tributaria. Por vía de interpretación sistemática el Consejo de Estado le otorgó cierta potestad tributaria al Presidente de la República y a la CREG.

Lo anterior supone el desconocimiento de tres principios constitucionales: (i) el de reserva de ley en materia tributaria, que restringe a la ley, como producto del Congreso de la República, la determinación de los hechos generadores de los tributos territoriales, (ii) el de predeterminación de los tributos: al establecer el hecho generador del impuesto sobre el alumbrado público en actos administrativos el Consejo de Estado reconoce que la labor del legislador es incompleta no pudiendo serlo, y (iii) el de representación popular de los tributos que exige "respetar la reserva competencial de los órganos de representación popular pluralistas para decretar, modificar o suprimir tributos" (Corte Constitucional, sentencia C-403, 2010).

12 Consejo de Estado. Sala de lo Contencioso Administrativo. Sección Cuarta. C.P.: Hugo Fernando Bastidas Bárcenas. Sentencia del 03 de diciembre de 2009. Rad.: 73001-23-31-000-2005-02632-01(16527).

13 Esta interpretación del Consejo de Estado ha sido reiterada en no menos de 12 sentencias. 
La última exigencia es una cara garantía obtenida por los liberales, que consagraron en el Bill of Rights como ilegal el "recaudar impuestos por y para el uso de la Corona bajo pretensión de prerrogativas, sin autorización del Parlamento".

A partir de la doctrina del "derecho viviente" desarrollada por la Corte Constitucional, cabía la posibilidad de demandar la interpretación del Consejo de Estado con la que construyó el hecho generador del impuesto de alumbrado público, a fin de que, junto con la disposición legal de la Ley 97 de 1913, fuese declara inexequible.

\subsection{La ley 1753 de 2015: superación de la inconstitucionalidad del impuesto sobre el servicio de alumbrado público}

Sin tener certeza de que la problemática hasta aquí expuesta hubiese calado en el Gobierno Nacional y en el Congreso de la República, lo cierto es que se intentó superar esta inconstitucionalidad, en la Ley 1753 de 2015. Allí el tributo sobre el impuesto al alumbrado público es sustituido por una "contribución especial con destinación específica" como fuente de financiamiento del servicio público de alumbrado público, que se considera ahora como especial. Esto es así, pues en el artículo 191 inciso tercero de la anotada ley se fijan dos hechos generadores de este tributo territorial: (i) consumir energía eléctrica, bien sea del servicio público domiciliario de energía electica o por autogeneración, y si no se consume, ese tributo se causa por (ii) ser propietario de inmuebles que causen el impuesto predial y se ubiquen "dentro de la jurisdicción del respectivo municipio o distrito". Sin embargo, dicha previsión legal fue declarada inexequible en Sentencia C-272 de 2016 pues la financiación del servicio público es incompatible con las contribuciones especiales.

Como reconocimiento de la posible discrepancia entre los hechos generadores previstos en la ley, con los establecidos en los diferentes acuerdos municipales, se da un año de plazo para que los Municipios adopten la contribución en su hecho generador y otros elementos a los términos de la Ley 1753 de 2015.

\section{CONCLUSIÓN}

Abrir la discusión hacia las mutaciones constitucionales permite que una Constitución no se desactualice y pierda su utilidad para dar respuesta a las necesidades históricas y políticas que surjan a lo largo de su vigencia, por ser ajena a la realidad en la que se aplica.A partir del estudio a la 96 
teoría dinámico-normativa de la mutación constitucional y los aportes realizados en las líneas precedentes, se demuestra con claridad que la mutación tiene la fuerza normativa suficiente para generar la inconstitucionalidad de elementos legales previos que no sean coherentes con el contenido normativo específico cambiado. En otras palabras, si una norma legal se corresponde frente a un contenido normativo específico anterior a una mutación constitucional, pero no cuando aquel muta debe ser expulsado del ordenamiento jurídico. La mutación implica cambios y si la ley preexistente no cabe en ese cambio debe invalidarse.

En este documento queda demostrada la ocurrencia de una mutación constitucional motivada por el cambio del precedente constitucional en relación potestad tributaria de las entidades territoriales que cambió el contenido normativo del principio de reserva de la ley estatutaria ocurrido en 2004 en relación a la potestad tributaria de las entidades territoriales. Desde ese entonces resultan ser contrarios a la Constitución colombiana de 1991 aquellos tributos territoriales que no tienen determinado el hecho generador en la ley, ni es determinable a partir de ella. El del alumbrado público fue uno de ellos.

En efecto, quedó claro que la regulación legal del impuesto sobre el servicio de alumbrado público de principios del siglo XX sufrió una inconstitucionalidad sobreviniente al sólo prever el objeto imponible y no el hecho gravable, a pesar de los ingentes esfuerzos del Consejo de Estado. Y de afrontar un nuevo control de constitucional, la Ley 97 de 1913 sería declarada inválida.

\section{REFERENCIAS BIBLIOGRÁFICAS}

Asamblea Nacional Constituyente,(1991). Gaceta Constitucional, Nº 1. Bogotá: Imprenta Nacional.

Colombia, Consejo de Estado. Sala de lo Contencioso Administrativo. Sección Cuarta. C.P: Ligia López Díaz. Rad.: 07001-23-15-0002005-00203-01(16170). Empresa de Energía de Arauca Vs. Municipio de Saravena.

Colombia, Consejo de Estado. Sala de lo Contencioso Administrativo. Sección Cuarta. C.P.: Ligia López Díaz. Sentencia del 04 de septiembre de 2008. Rad.: 76001-23-31-000-2005-0458201(16850). 
Colombia, Consejo de Estado. Sala de lo Contencioso Administrativo. Sección Cuarta. C.P: Martha Teresa Briceño de Valencia. Sentencia del 09 de julio de 2009. Rad.: 17001-23-31-000-200600404-02 (16544). Néstor Fabio Valencia Torres y otro Vs. Municipio de Manizales.

Colombia, Consejo de Estado. Sala de lo Contencioso Administrativo. Sección Cuarta. C.P.: Hugo Fernando Bastidas Bárcenas. Sentencia del 11 de marzo de 2010. Rad.: 54001-23-31-000-200401079-00(16667).

Colombia, Consejo de Estado. Sala de lo Contencioso Administrativo. Sección Cuarta. C.P.: Hugo Fernando Bastidas Bárcenas. Sentencia del 03 de diciembre de 2009. Rad.: 73001-23-31-0002005-02632-01(16527).

Colombia, Corte Constitucional. Auto 223 de 2006 (M.P.: Jaime Córdoba Triviño)

Colombia, Corte Constitucional. C-084 de 1995 (M.P.: Alejandro Martínez Caballero)

Colombia, Corte Constitucional. C-537 de 1995 (M.P.: Hernando Herrera Vergara)

Colombia, Corte Constitucional. C-155 de 1999 (M.P.: Vladimiro Naranjo Mesa)

Colombia, Corte Constitucional. C-504 de 2002 (M.P.: Jaime Araujo Rentería)

Colombia, Corte Constitucional. C-1043 de 2003 (M.P.: Jaime Córdoba Triviño)

Colombia, Corte Constitucional. C-992 de 2004 (M.P.: Humberto Sierra Porto)

Colombia, Corte Constitucional. C-035 de 2009 (M.P.: Marco Gerardo Monroy Cabra)

Colombia - Corte Constitucional. C-287 de 2009 (M.P.: Luís Ernesto Vargas Silva)

Colombia - Corte Constitucional. C-588 de 2009 (M.P.: Gabriel Eduardo Mendoza Martelo) 
Colombia, Corte Constitucional. C-403 de 2010 (M.P.: María Victoria Calle Correa)

Colombia, Ley 97 de 1913, de 24 de noviembre, que da autorizaciones especiales a ciertos Concejos Municipales. Diario Oficial, 04 de diciembre de 1913, núm. 15.062.

Colombia, Ley 84 de 1915, de 30 de noviembre, por la cual se reforman y adicionan las Leyes 4 y 97 de 1913. Diario Oficial, 13 de diciembre de 1915, núm. 15.667.

Colombia, Ley 1753 de 2015, de 09 de junio, por la cual se expide el Plan Nacional de Desarrollo 2014-2018 "Todos por un nuevo país". Diario Oficial, 09 de junio de 2015, núm. 49.538.

López, C. (2015). Mutación de los derechos fundamentales por la interpretación de la Corte Constitucional colombiana. Concepto, justificación y límites. Bogotá: Universidad Externado de Colombia.

Robledo, P. (2010). La autonomía municipal en Colombia. Bogotá: Universidad Externado de Colombia.

Sierra Porto, H. (1998). La reforma de la Constitución. Bogotá: Universidad Externado de Colombia. 